\section{Influenza vaccination of healthy adults was effective during the 1998-9 flu season but not the 1997-8 season}

Bridges CB, Thompson WW,Meltzer MI, et al. Effectiveness and cost-benefit of influenza vaccination of healthy working adults. A randomized controlled trial.JAMA 2000 Oct 4;284:1655-63.

\section{QUESTION: Is influenza vaccination effective for preventing influenza-like illness (ILI) in healthy working adults?}

\section{Design}

Randomised \{allocation concealed*\}†, blinded (patients and clinicians),* controlled trial done during the flu seasons of 1997-8 and 1998-9.

\section{Setting}

Dearborn, Michigan, USA.

\section{Participants}

2375 healthy adults who were 18-64 years of age, were full time employees of the Ford Motor Company, and did not have any medical condition for which influenza vaccine was recommended or any contraindications to vaccination. 1184 adults (mean age 44 y, 79\% men) participated during 1997-8, with 95\% follow up, and 1191 (mean age 44 y, 76\% men) participated during 1998-9, with $99 \%$ follow up.

\section{Intervention}

During the 1997-8 flu season, 595 adults were allocated to trivalent inactivated influenza vaccine, and 589 were allocated to a placebo injection of sterile saline. During the 1998-9 season, 587 were allocated to influenza vaccine, and 604 were allocated to placebo.

\section{Main outcome measures}

Patient reports of ILI (feverishness or temperature $\geqslant 100^{\circ} \mathrm{F}$ plus cough or sore throat) and associated physician visits and lost work days during the influenza period.

\section{Main results}

During 1997-8, vaccine efficacy (based on recipients with laboratory confirmed influenza illness) was 50\% (table). Vaccine recipients reported 38\% more ILI related sick days $(\mathrm{p}=0.01), 45 \%$ more lost work days $(p=0.047)$, and $378 \%$ more lost work hours for physician visits $(\mathrm{p}<0.001)$ than placebo recipients; ILIs and physician visits did not differ. During 1998-9, vaccine efficacy was $86 \%$ (table). Vaccine recipients reported 34\% fewer ILIs and 34\% fewer related sick days $(\mathrm{p}<0.001$ for both), $42 \%$ fewer physician visits $(\mathrm{p}<0.001), 32 \%$ fewer lost work days $(\mathrm{p}=0.002)$, and $47 \%$ fewer lost hours for physician visits $(\mathrm{p}<0.001)$.

\section{Conclusion}

Influenza vaccination did not prevent influenza-like illness in healthy working adults during the 1997-8 flu season but was effective during the 1998-9 flu season.
*See glossary. $\uparrow$ Information provided by author.

For correspondence: Dr C B Bridges,

Influenza Branch, $M S$ A-32, Division of Viral and Rickettsial

Diseases, National Center for Infectious Diseases, Centers for Disease Control and Prevention, 1600 Clifton Road, Atlanta, GA 30333, USA.

Vaccine v placebo for laboratory confirmed influenza illness

\begin{tabular}{llrll} 
Year & Vaccine & Placebo & RRR $(95 \%$ CI) & NNT (CI) \\
\hline $1997-8$ & $2.2 \%$ & $4.4 \%$ & $50 \%(-77$ to 86$)$ & Not significant \\
\hline $1998-9$ & $1.4 \%$ & $10.2 \%$ & $86 \%(47$ to 96$)$ & $12(7$ to 27$)$ \\
\hline
\end{tabular}

¥Abbreviations defined in glossary; RRR, $\mathrm{Cl}$, and NNT calculated from data in article.

\section{COMMENTARY}

Influenza vaccination is clinically effective and cost effective in older people. ${ }^{1}$ Using relatively conservative estimates of $40 \%$ for reducing admission to hospital and death, influenza vaccination results in a savings of US $\$ 2.32$ per Medicare beneficiary. ${ }^{2}$ Furthermore, the cost per year of life gained is $\$ 145$. These savings were calculated by subtracting hospital payment savings (for admission for pneumonia treatment) from vaccine programme costs.

Admission to hospital for influenza, is rare, however, in young, healthy adults, so cost effectiveness is harder to determine. Economic benefits are calculated by balancing the increased costs of vaccination (because of the need to take time off from work) with direct (physician visits and prescriptions) and indirect costs (lost time from work) from an influenza illness.

A previous randomised trial by Nichol $e t$ al suggested that vaccination of healthy, working adults would save $\$ 47$ per vaccinee. ${ }^{3}$ This analysis was limited by a relatively high calculated influenza attack rate $(35 \%)$ that was determined by telephone interviews. ${ }^{4}$ To determine the generalisability of Nichol's findings, Bridges $e t$ al studied the clinical effectiveness and societal cost benefit of influenza vaccination over a 2 year period. Influenza infection was laboratory confirmed in a subset of patients. In the first year of the study, the vaccine and the most common circulating influenza virus were a poor match; this problem occurs about once every 10 years. Influenza vaccination provided neither clinical nor economic benefit in that year. In the second year of the study, vaccine efficacy was $86 \%$ (well in line with the typical $70 \%$ to $90 \%$ efficacy rate) with a more characteristic attack rate of $10 \%$. Even in this year, vaccinating young, healthy adults against influenza resulted in a net cost of about $\$ 11$ per vaccinee.

These data verify the clinical benefits of influenza vaccination, so physicians may confidently recommend vaccination for "any person who wishes to reduce the likelihood of becoming ill with influenza." ${ }^{5}$ Unfortunately, no net societal economic benefit may be derived from vaccinating young, healthy people. Sometimes doing the right thing costs us money.

Bradley S Bender, MD Veterans Affairs Medical Center Gainesville, Florida, USA

1 Nichol KL, Margolis KL, Wuorenma J, et al. The efficacy and cost effectiveness of vaccination against influenza among elderly persons living in the community. $N$ Engl J Med 1994;331:778-84.

2 Final results: Medicare influenza demonstration--selected states, 1988-1992. MMWR Morb Mortal Wkly Rep 1993;42:601-4.

3 Nichol KL, Lind A, Margolis KL, et al. The effectiveness of vaccination against influenza in healthy, working adults. $N$ Engl J Med 1995;333:889-93.

4 Patriarca PA, Strikas RA. Influenza vaccine for healthy adults? N Engl J Med 1995;333:933-4.

5 Prevention and control of influenza: recommendations of the advisory committee on immunization practices (ACIP). MMWR Morb Mortal Wkly Rep 2000;49:1-38. 